Bioscientia Medicina: Journal of Biomedicine \& Translational Research

Journal Homepage: www.bioscmed.com

\title{
Lactobacillus Reuteri DSM 17938 in Infantile Colic: A Systematic Review and Meta-Analysis \\ Burhannudin Ichsan $^{1^{*}}$, Nining Lestari ${ }^{2}$, Sulistyani ${ }^{3}$ \\ ${ }^{1}$ Department of Public Health/Community Medicine, Faculty of Medicine, Universitas Muhammadiyah Surakarta, Surakarta, Indonesia \\ 2 Department of Public Health, Faculty of Medicine, Universitas Muhammadiyah Surakarta, Surakarta, Indonesia \\ ${ }^{3}$ Department of Neurology, Faculty of Medicine, Universitas Muhammadiyah Surakarta, Surakarta, Indonesia
}

\section{A R T I C L E I N F O}

\section{Keywords:}

Lactobacillus reuteri DSM 17938

Infantile colic

Meta-analysis

Systematic review

*Corresponding author:

Burhannudin Ichsan

\section{E-mail address:}

bi268@ums.ac.id

All authors have reviewed and approved the final version of the manuscript.

https://doi.org/10.37275/bsm.v6i3.457

\begin{abstract}
A B S T R A C T
Background. Infantile colic, defined as paroxysmal, excessive, and consolable crying without an identifiable cause. It is common in the first 3 months of life. There have been many RCT studies conducted. A systematic synthesis is required to summarize the results of these RCTs. This study was aimed to systematically analyze the benefits of Lactobacillus reuteri DSM 17938 for infantile colic.

Methods: This systematic review and meta-analysis used keywords: ("infantile colic" OR "abdominal cramps" OR "abdominal cramp" OR "infant colic") AND "lactobacillus reuter" AND (placebo OR placebos) AND ("randomized controlled trial" OR RCT). The databases used were: pubmed, science direct, and google scholar. Meta-analysis was conducted to combine the articles. The eligibility criteria were: patient with infantile colic, intervention with $L$. reuteri DSM 17938 , control was placebo, RCT study design, outcome with dichotomous scale, all races, all ethnicities, all countries, all genders, in English, and not limited by year.

Results: The search resulted in 800 articles. After reducing duplication, the number of articles was 747 . Screening with titles and abstracts resulted in 13 full teks articles. Six articles fitted the eligibility criteria. The results of the metaanalysis were as follows. The forest plot showed that the combined effect of the six articles showed an RR of 0.47 and was statistically significant $(p<0.001)$.

Conclusion: Based on the results of this meta-analysis, L. reuteri DSM 17938 is recommended for infants with infantile colic. There were no significant side effects with the use of $L$. reuteri DSM 17938 on infantile colic.
\end{abstract}

\section{Introduction}

Infantile colic is crying or fussing more than 3 hours a day, more than 3 days a week, for no apparent reason, and cannot be prevented or stopped by the caregiver. Although infantile colic can heal on its own and is a mild disorder, it is one of the most common problems in the early 4 months of life. ${ }^{1}$

Although infantile colic resolves spontaneously after 3 or 4 months of age, it is associated with maternal depression, early cessation of breastfeeding, and shaken baby syndrome. ${ }^{2}$ Infantile colic affects nearly $10 \%$ to $40 \%$ of infants worldwide, and is associated with parental frustration and repeated doctor visits. ${ }^{3}$

Infantile colic has been classified as a functional digestive disorder whose pathogenesis is still unknown, despite decades of research. As a result, various treatments have been tried to relieve the condition. ${ }^{3}$ 
One treatment that is often used is Lactobacillus reuteri which is a type of probiotics.

Probiotics are live microorganisms. ${ }^{4}$ Probiotics are products that contain specific strains of bacteria that are beneficial for health. ${ }^{5}$ L. reuteri DSM 17938 is a probiotic which is well-known to have benefits for several digestive diseases. ${ }^{6}$ L. reuteri DSM 17938 is a daughter strain of Lactobacillus reuteri ATCC 55730.7 The $L$. reuteri strains produce Reuterin. Reuterin is a broad-spectrum antimicrobial that can inhibit the growth of various spectrums of microorganisms such as gram-positive bacteria, gram-negative bacteria, fungi, and parasites. L. reuteri strains may also regulate the immune response. 8 Some of the reported benefits include improvement of intestinal health, infantile colic, functional constipation, etc. Because of this, currently, L. reuteri is commercially available in 99 countries. 9

Various studies have been conducted to analyze the efficacy of $L$. reuteri to treat infantile colic. Several studies gave different results.

Sung et al (2014) conducted an RCT study to analyze the efficacy of $L$. reuteri DSM 17938 in the treatment of infantile colic. The results showed that $L$. reuteri DSM 17938 had no benefit in infantile colic infants in the community, either in infants who were breastfed or formula-fed. ${ }^{2}$ Chau et al (2015) conducted an RCT study to compare L. reuteri DSM 17938 and placebo against infantile colic. The results showed that L. reuteri DSM 17938 could significantly improve infantile colic symptoms. ${ }^{10}$ Szajewska et al (2013) conducted an RCT study to see the efficacy of $L$. reuteri DSM 17938 compared to placebo in treating infantile colic. The results showed that exclusively breastfed or predominantly breastfed infants suffering from infantile colic benefited from the administration of $L$. reuteri DSM 17938.11 Sung et al (2018) compiled a meta-analysis to find out the combined effect of the research that has been done. The results of the study concluded that $L$. reuteri DSM 17938 is effective and can be recommended for infants fed breast milk, while the benefits for infants fed formula still require further research. 12

This systematic review and meta-analysis aims to re-analyze the combined effects of the studies that have been carried out. It is hoped that there will be new RCT studies to see the consistency of the results from the previous meta-analysis. This study aims to prove the benefits of $L$. reuteri DSM 17938 which in theory can be useful for infantile colic.

\section{Methods}

\section{Eligibility criteria}

Eligibility criteria in this systematic review were: patient with infantile colic, intervention with $L$. reuteri DSM 17938, control was placebo, RCT design, outcome with dichotomous scale, all races, all ethnicities, all countries, all genders, in English, and not limited by year. The exclusion criteria in this study were: preprints, theses, dissertations, and posters.

\section{Information sources and searches}

The electronic databases used are: pubmed, science direct, and google scholar. The keywords used are: ("infantile colic" OR "abdominal cramps" OR "abdominal cramp" OR "infant colic") AND "lactobacillus reuteri" AND (placebo OR placebos) AND ("randomized controlled trial" OR RCT).

\section{Studies selection}

The selection of studies was carried out as follows. The combination of keywords was entered into the three databases mentioned above. The search results from the three databases were combined into one. The combined titles of the articles obtained were identified as duplications. Duplicate articles were removed. The next stage was to screen titles and or abstracts based on eligibility criteria. Titles and or abstracts that did not meet the eligibility criteria were removed. The next step was to download the full text article to be screened based on the eligibility criteria. Finally, several full text articles were obtained that met the eligibility criteria.

\section{Data collection and data items}

Extraction of data from the study was done by creating a table. The table contains: author and year, country, research objectives, summary of the research, and number of samples. 


\section{Risk of bias for included studies}

The articles obtained were critically appraised using the CASP Randomized Controlled Trial Standard Checklist. 13

\section{Analysis}

The analysis in this systematic review used metaanalysis and narrative analysis.

\section{Results}

\section{Study selection}

A search on three databases yielded the following number of articles: google scholar (730), pubmed (11), and science direct (59). The total number of article titles obtained was 800. After deducting duplication, the number of articles was 747 . Screening of titles and or abstracts based on eligibility criteria produced 13 articles. All 13 articles were downloaded. After adjusting for the eligibility criteria, 6 articles were obtained for synthesis. Figure 1 shows the study selection process.

Literature seacrh: e-databases: Google scholar, Science Direct, Pubmed

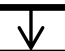

Combined search results: 800

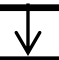

The articles identified duplication

$\checkmark$

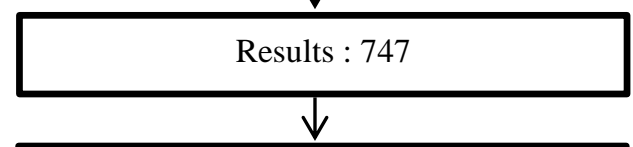

Articles screened by title and/or abstract

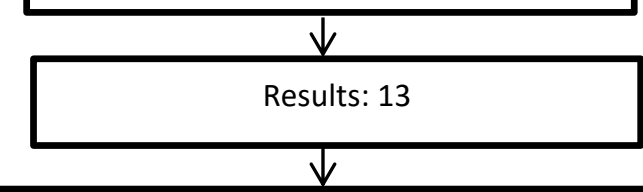

Full text articles are seen as conformity with the eligibility criteria

\begin{tabular}{|l|} 
Excluded $(\mathrm{n}=7)$ \\
$\begin{array}{l}\text { Combined Probiotic }(\mathrm{n}=2), \text { Editorial } \\
(1), \text { Commentary }(1), \text { Strain L reuteri } \\
\text { other than DSM } 17938(1), \text { there is no } \\
\text { outcome in the form of dichotomous }\end{array}$ \\
\hline Articles included in the analysis $(\mathrm{n}=6)$
\end{tabular}

Figure 1. PRISMA flow chart of selected studies

\section{Study characteristics}

systematic review are shown in table 1 below.

The characteristics of the articles obtained in this 
Table 1. Article characteristics

\begin{tabular}{|c|c|c|c|c|}
\hline Author & Setting & Objective & $\begin{array}{l}\text { Sample } \\
\text { size }\end{array}$ & Summary of the research \\
\hline $\begin{array}{l}\text { Savino et al } \\
(2018)^{1}\end{array}$ & Italy & $\begin{array}{l}\text { Analyzing differences in crying } \\
\text { time, gut microbiota and fecal } \\
\text { calprotectin in infants with } \\
\text { infantile colic between those given } \\
\text { L. reuteri and placebo. }\end{array}$ & 60 & $\begin{array}{l}\text { Infants with infantile colic were } \\
\text { randomized to receive } \\
\text { Lactobacillus reuteri or placebo } \\
\text { for one month. The outcomes } \\
\text { measured were: daily crying } \\
\text { time, FOXP3 and RORy } \\
\text { messenger } \quad \text { RNA, gut } \\
\text { microbiota, and } \\
\text { Calprotectin. }\end{array}$ \\
\hline $\begin{array}{l}\text { Mi et al } \\
(2015)^{14}\end{array}$ & China & $\begin{array}{l}\text { Analyzing the benefits of } L \text {. reuteri } \\
\text { for the treatment of infantile colic }\end{array}$ & 39 & $\begin{array}{l}\text { Exclusively breastfed or } \\
\text { predominantly breastfed } \\
\text { infants with infantile colic were } \\
\text { recruited for the study. The } \\
\text { infants were randomized to } \\
\text { receive } L \text {. reuteri or placebo for } \\
21 \text { days. Outcome } \\
\text { measurement was after } 4 \\
\text { weeks. Outcomes measured } \\
\text { were reduced crying time, } \\
\text { parental satisfaction, and } \\
\text { decreased maternal } \\
\text { depression. }\end{array}$ \\
\hline $\begin{array}{l}\text { Szajewska et } \\
\text { al }(2013)^{11}\end{array}$ & Poland & $\begin{array}{l}\text { To analyze whether the } \\
\text { administration of } L \text {. reuteri is } \\
\text { beneficial for breastfed infants who } \\
\text { suffer from infantile colic. }\end{array}$ & 80 & $\begin{array}{l}\text { Infants, both exclusively } \\
\text { breastfed and those given } \\
\text { predominantly breast milk, } \\
\text { were randomized to receive } L \text {. } \\
\text { reuteri or placebo. The outcome } \\
\text { measured was a decrease in } \\
\text { crying duration on days } 7,14 \text {, } \\
21 \text {, and } 28 \text {. }\end{array}$ \\
\hline $\begin{array}{l}\text { Savino et al } \\
(2010)^{15}\end{array}$ & Italy & $\begin{array}{l}\text { Analyzing the efficacy of } L . \text { reuteri } \\
\text { for infantile colic and to evaluate its } \\
\text { relationship to the gut microbiota. }\end{array}$ & 46 & $\begin{array}{l}\text { Exclusively breastfed infants } \\
\text { with infantile colic were } \\
\text { randomized to either } L \text {. reuteri } \\
\text { or placebo for } 21 \text { days. The } \\
\text { outcomes measured were the } \\
\text { duration of crying and fecal } \\
\text { Escherichia coli. }\end{array}$ \\
\hline $\begin{array}{l}\text { Chau et al } \\
(2015)^{10}\end{array}$ & Canada & $\begin{array}{l}\text { Analyzing the effectiveness of } L \text {. } \\
\text { reuteri for the treatment of infantile } \\
\text { colic in breastfed infants. }\end{array}$ & 52 & $\begin{array}{l}\text { Infants with infantile colic were } \\
\text { randomized to receive } L \text {. reuteri } \\
\text { or placebo for } 21 \text { days. } \\
\text { Outcomes measured were daily } \\
\text { crying and fussing. }\end{array}$ \\
\hline $\begin{array}{l}\text { Sung et al } \\
(2014)^{2}\end{array}$ & Australia & $\begin{array}{l}\text { Analyzing whether L. reuteri } \\
\text { reduced crying or fussiness in the } \\
\text { general population of infants less } \\
\text { than } 3 \text { months of age with infantile } \\
\text { colic either breastfed or formula- } \\
\text { fed. }\end{array}$ & 127 & $\begin{array}{l}\text { Infants with infantile colic aged } \\
\text { less than } 3 \text { months were } \\
\text { randomized to receive } L \text {. reuteri } \\
\text { or placebo. The babies sampled } \\
\text { were babies who were breastfed } \\
\text { or formula-fed. The intervention } \\
\text { was given for one month. The } \\
\text { primary outcome measured was } \\
\text { the duration of crying or fussing } \\
\text { at one month. }\end{array}$ \\
\hline
\end{tabular}

Table 1 shows the characteristics of each study.

The studies synthesized in this systematic review came from four continents, namely Europe, Australia, America, and Asia. There were no articles from the
African continent yet. All articles were still from developed countries. The total research sample was 404. 
Table 2 shows the risk of bias from the synthesized studies, while table 3 shows the RCT critical appraisal

Table 2. Risk of bias of studies using instruments from CASP. ${ }^{13}$

\begin{tabular}{|l|l|l|l|l|l|l|l|l|l|l|l|l|}
\hline \multicolumn{1}{|c|}{ Author } & \multicolumn{9}{|c|}{ Item } & \multicolumn{1}{|c|}{} \\
\cline { 2 - 11 } & 1 & 2 & 3 & 4 & 5 & 6 & 7 & 8 & 9 & 10 & 11 \\
\hline $\begin{array}{l}\text { Savino et al } \\
(2018)\end{array}$ & Yes & Yes & No & Yes & Yes & Yes & Yes & Yes & Yes & Yes & Yes \\
\hline Mi et al (2015) & Yes & Yes & No & No & $\begin{array}{l}\text { Can't } \\
\text { tell }\end{array}$ & Yes & Yes & No & Yes & Yes & Yes \\
\hline $\begin{array}{l}\text { Szajewska et al } \\
(2013)\end{array}$ & Yes & Yes & No & Yes & Yes & Yes & Yes & Yes & Yes & Yes & Yes \\
\hline $\begin{array}{l}\text { Savino et al } \\
(2010)\end{array}$ & Yes & Yes & Yes & Yes & Yes & Yes & Yes & No & Yes & Yes & Yes \\
\hline $\begin{array}{l}\text { Chau et al } \\
(2015)\end{array}$ & Yes & Yes & No & Yes & Yes & Yes & Yes & Yes & Yes & Yes & Yes \\
\hline Sung et al (2014) & Yes & Yes & No & Yes & Yes & Yes & Yes & Yes & Yes & Yes & Yes \\
\hline
\end{tabular}

The results of the risk of bias or critical appraisal of each study show that in general the quality of all studies is good. This is indicated by the answer yes to almost all questions on critical appraisal items in almost all studies.

Some notes on the risk of bias are explained as follows. There was one study that did not apply a double blind but only a single blind, namely the study of Mi et al (2015). ${ }^{14}$ On average, the studies did not apply the intention to treat analysis but per protocol analysis. All studies were RCTs, meeting the eligibility criteria for this meta-analysis.

\section{Meta analysis of included studies}

The screening results of 800 articles resulted in 6 studies that met the eligibility criteria. The six studies were then analyzed together to obtain a combined effect.

The outcome analyzed together was responder which defined as a 50\% reduction in crying duration from baseline. Others were classified as events. Table 3 below is the data that can be used as material for meta analysis using the Revman 5.4 application. The forest plot is shown in Figure 1.

Table 3. Summary of responders and events in the six studies included in the meta-analysis.

\begin{tabular}{|c|c|c|c|c|c|c|c|c|}
\hline No & Authors & $\begin{array}{l}\text { Experimental } \\
\text { sample }\end{array}$ & $\begin{array}{l}\text { Control } \\
\text { sample }\end{array}$ & $\begin{array}{l}\text { Experimental } \\
\text { Responder }\end{array}$ & $\begin{array}{l}\text { Control } \\
\text { Responder }\end{array}$ & $\begin{array}{l}\text { Experimental } \\
\text { events }\end{array}$ & $\begin{array}{l}\text { Control } \\
\text { events }\end{array}$ & $\begin{array}{l}\text { Measured } \\
\text { on day }\end{array}$ \\
\hline 1 & $\begin{array}{l}\text { Savino et al } \\
(2018)\end{array}$ & 32 & 22 & 24 & 8 & 8 & 14 & 30 \\
\hline 2 & Mi et al (2015) & 20 & 19 & 18 & 1 & 2 & 18 & 21 \\
\hline 3 & $\begin{array}{l}\text { Szajewska et } \\
\text { al (2013) }\end{array}$ & 40 & 40 & 39 & 15 & 1 & 25 & 21 \\
\hline 4 & $\begin{array}{l}\text { Savino et al } \\
(2010)\end{array}$ & 25 & 21 & 24 & 15 & 1 & 6 & 21 \\
\hline 5 & $\begin{array}{l}\text { Chau et al } \\
(2015)\end{array}$ & 24 & 28 & 17 & 6 & 7 & 22 & 21 \\
\hline 6 & $\begin{array}{l}\text { Sung et al } \\
(2014)\end{array}$ & 67 & 60 & 27 & 29 & 40 & 31 & 30 \\
\hline
\end{tabular}

Table 3 shows that in most studies, outcomes were measured on day 21. Two studies were taken on day 30. As an additional explanation, although there were outcomes on other days, they were not displayed in this systematic review so that the results were more focused. 


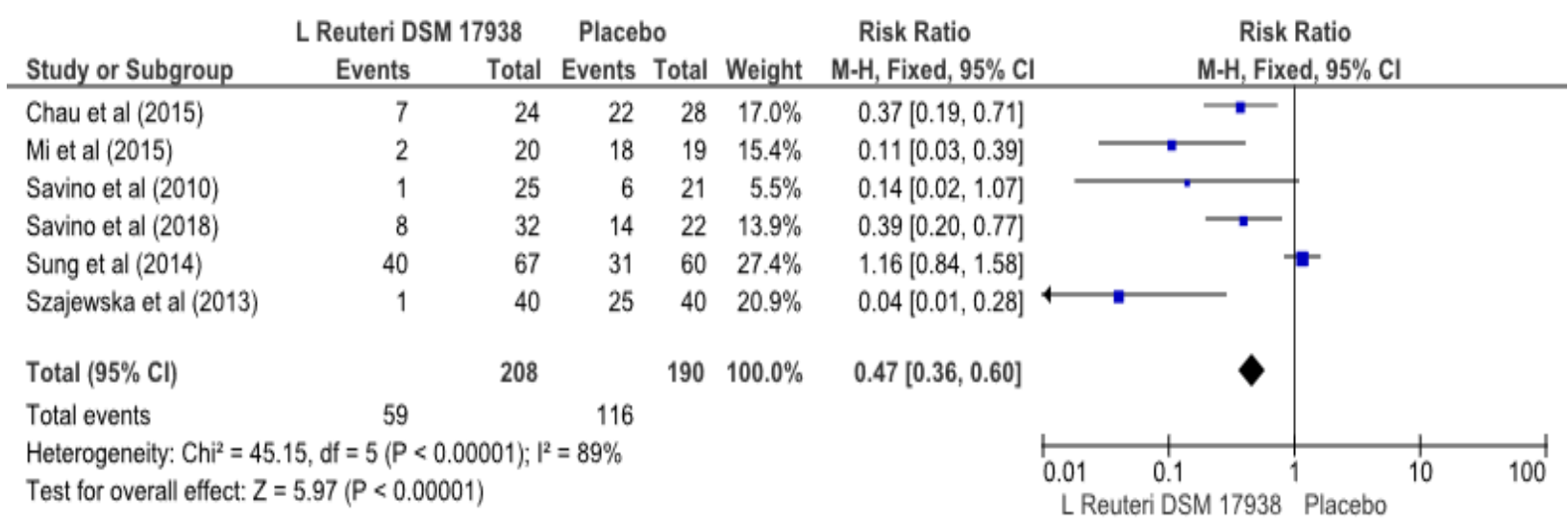

Figure 2. Forest plot of included studies

Figure 2 shows the forest plot results from the studies included in the analysis. If we look at each study, 4 studies produced statistically significant results and there were two studies that produced statistically insignificant results.

The results of two studies that were not statistically significant were Savino et al (2010) ${ }^{15}$, and Sung et al (2014). ${ }^{2}$ The non-significant results in each study can be seen from the $95 \%$ CI that crosses the number 1 or the horizontal line that crosses the vertical line.

The combined results showed an RR of 0.47 and statistically significant $(\mathrm{p}<0.001)$. This means that infants with infantile colic who were given $L$. reuteri DSM 17938 had a 0.47 chance of not recovering compared to those given placebo and it was statistically significant. This analysis uses a random effect model because $\mathrm{I}^{2}>50 \%$, i.e. $89 \%$.

\section{Other results}

Some of the other results can be seen in table 4 below.

Table 4. Other results from included studies

\begin{tabular}{|c|c|}
\hline Authors & Other results \\
\hline Savino et al (2018) & $\checkmark \quad$ Lowering fecal Calprotectin \\
\hline Mi et al (2015) & $\begin{array}{ll}\checkmark & \text { Parental satisfaction was significantly higher in the intervention group } \\
\checkmark & \text { There was a significant improvement in maternal depression in the intervention group }\end{array}$ \\
\hline Szajewska et al (2013) & - \\
\hline Savino et al (2010) & $\begin{array}{ll}\checkmark & \text { There was a significant increase in fecal Lactobacillus in the intervention group } \\
\checkmark & \text { There was a reduction in Eschericha coli and fecal ammonia in the intervention group } \\
\checkmark & \text { There were no side effects related to supplementation }\end{array}$ \\
\hline Chau et al (2015) & - \\
\hline Sung et al (2014) & $\checkmark \quad$ There were no side effects related to supplementation \\
\hline
\end{tabular}

Table 4 shows that no side effects were observed during the study. Other results that can be obtained are as follows. There was a decrease in fecal calprotectin as an indicator of intestinal inflammation. There was parental satisfaction and improvement in maternal depression. There was an increase in fecal Lactobacillus and a decrease in fecal Escherichia colic.

\section{Discussion}

The results of this meta-analysis indicate that $L$. reuteri DSM 17938 can be used to treat infants with infantile colic. There were no significant side effects with the use of $L$. reuteri DSM 17938 on infantile colic.

There are slight differences in the criteria for infantile colic in each study, but in general, the criteria 
were the same. Savino et al (2018) define infantile colic as crying or fussing more than 3 hours a day and more than 3 days a week for no apparent reason and cannot be prevented or stopped by caregivers. ${ }^{1}$ Mi et al (2015) defined infantile colic as crying episodes for at least 3 hours a day for at least 3 days before starting the study. ${ }^{14}$ Szajewska et al (2013) defined infantile colic as crying episodes for at least 3 hours a day and occurring at least 3 days a week in the 7 days before the study. ${ }^{11}$ Savino et al (2010) defined infantile colic with modified Wessel criteria, namely: fussy crying episodes lasting at least 3 hours a day for at least 3 days a week in the week before the study. ${ }^{15}$

This meta-analysis only combined outcomes with a dichotomous scale that was responder or not. Outcomes with continuous scales such as the mean average crying per day were not analyzed in this metaanalysis.

The benefits of probiotics for humans include the improvement of the immune system, synthesis of components that provide anti-cholesterol, anticarcinogenic properties, improvement of intestinal flora with the resulting anti-microbial, treatment of several intestinal disorders, good effects for systemic diseases such as allergies or inflammation. ${ }^{16}$ The most widely used probiotics are Lactobacilli and Bifidobacterium. ${ }^{17}$ L. reuteri DSM 17938 is a new probiotic strain that does not carry potentially transferable traits for Tetracycline and Lincomycin resistance. L. reuteri is used for the treatment of gastroenteritis in children. The potential mechanism is its anti-inflammatory effect, as some publications were showing the anti-inflammatory effect of this probiotic in neonatal animals. There was also evidence of inflammation in infants with colic, and current evidence suggests that probiotics may also be beneficial for infants with colic. ${ }^{18}$ Some related systematic review or meta-analysis studies are as follows.

Sung et al (2018) conducted a meta-analysis to analyze the benefits of $L$. reuteri DSM 17938 in treating infantile colic. There were 4 studies included in the analysis. The total number of research samples was 345 infants. The results showed that $L$. reuteri DSM 17938 was effective and could be recommended for infantile colic breastfed infants. The role of $L$. reuteri DSM 17938 for infantile colic infants with formula milk still requires further research. 12

Gutiérres-Castrellón et al (2017) conducted a systematic review to compare the benefits of L. reuteri DSM 17938 with other interventions in treating infantile colic. The results showed that $L$. reuteri DSM 17938 and several dietary approaches were better than other interventions. ${ }^{19}$

Szajewska \& Dryl (2018) conducted a systematic review to assess the benefits of probiotic supplementation in the management of infantile colic. The results showed that some probiotics, especially $L$. reuteri DSM 17938, might be considered for infantile colic therapy, while data for other probiotics were still limited. 20

$\mathrm{Xu}$ et al (2015) conducted a systematic review to analyze the benefits of $L$. reuteri DSM 17938 on the management of infantile colic. There were 6 studies included in the analysis. The total number of research samples was 423 infants. The results showed that $L$. reuteri DSM 17938 had potential in the management of infantile colic in the second and third weeks without causing bad side effects. ${ }^{18}$

The results of this systematic review are consistent with the results of similar studies conducted previously. The results of this systematic review add to RCTs that have not been obtained in previous systematic review studies such as Savino et al (2018). ${ }^{1}$

\section{Conclusion}

After adjusting for the eligibility criteria, 6 articles were obtained for synthesis. L. reuteri DSM 17938 has potential benefits for the management of infantile colic. There were no significant side effects with the use of Lactobacillus reuteri DSM 17938 on infantile colic.

\section{References}

1. Savino, F., Garro, M., Montanari, P., Galliano, I., \& Bergallo. M. Crying time and RORY/FOXP3 expression in Lactobacillus reuteri DSM 17938treated infants with colic: a randomized trial. J Pediatr 2018; 192: 171-7. https://doi.org10.1016/j.peds.2017.08.062. 
2. Sung, V., Hiscock, H., Tang, M.L.K., Mensah, F.K., Nation, M.L., Satzke, C., Heine, R.G., Stock, A., Barr, R.G., \& Wake, M. Treating infant colic with the probiotik Lactobacillus reuteri: double blind, placebo controlled randomised trial. BMJ 2014; 348: g2107. Doi: 10.1136/bmj.g2107.

3. Baldassarre, M.E., Mauro, A.D., Tafuri, S., Rizzo, V., Gallone, M.S., Mastromarino, P., Capobianco, D., Laghi, L., Zhu, C., Capozza, M., \& Laforgia, N. Effectiveness and safety of a probiotik-mixture for the treatment of infantile colic: a double-blind, randomized, placebocontrolled clinical trial with fecal real-time PCR and NMR-based metabolomics analysis. Nutrients 2018; 10, 195; doi: 10.3390/nu10020195.

4. Agustinus, T., Simadibrata, M., Hasan, I., \& Shatri, H. Randomized double-blind controlled trial: Benefits of Lactobacillus Reuteri in Chronic Functional Constipation Patients. The Indonesian Journal of Gastroenterology, Hepatology and Digestive Endoscopy 2015, December; 16(3).

5. Widyarman, A.S., Pranoto, S., Theodorea, C.F., Bachtiar, E.W., \& Bachtiar, B.M. Isolation and identification of Indonesian Lactobacillus Reuteri Strain from the Saliva of Young Adults. Scientific Dental Journal 2018; 02: 67-75. Doi: http://dx.doi..org/10.26912/sdj.v2i2.2840.

6. Saviano, A., Brigida, M., Migneco, A., Gunawardena, G., Zanza, C., Candelli, M., Franceschi., \& Ojetti, V. Lactobacillus Reuteri DSM 17938 (Limosilactobacillus reuteri) in Diarrhea and Constipation: Two Side of the Same Coin?: Review. Medicina 2021; 57, 643. https://doi.org/10.3390/medicina57070643.

7. Urbańska, M., \& Szajwska, H. The Efficacy of Lactobacillus reuteri DSM 17938 in Infants and Children: a Review of The Current Evidence. Eur J Pediatr 2014; 173: 1327-1337. Doi: 10.1007/s00431-014-2328-0.

8. Szyman'ski, H., \& Szajewska, H. Lack of Efficay of Lactobacillus Reuteri DSM 17938 for the Treatment of Acute Gastroenteritis: a
Randomized Controlled Trial. Pediatr Infect Dis

J 2019; 38: e237-e242. Doi: 10.1097/INF.00000000000002355.

9. Srinivasan, R., Kesavelu, D., Veligandla, K.C., Muni, S.K., Mehta, S.C. Lactobacillus Reuteri DSM 17938: Review of Evidence in Functional Gastrointestinal Disorders. Pediatr Ther 2018; 8(3): 1000350 . Doi: $10.4172 / 2161-$ 0665.1000350.

10.Chau, K., Lau, E., Greenberg, S., Jacobson, S., Brojeni, P.Y., Verma, N., \& Koren, G. Probiotics for infantile colic: a randomized, double-blind, placebo-controlled trial investigating lactobacillus reuteri DSM 17938. J Pediatr 2015; 166:

74-8. http://dx.doi.org/10.1016/j.jpeds.2014.09.020

11.Szajewska, H., Gyrczuk, E., \& Horvath, A. Lactobacillus reuteri DSM 17938 for the management of infantile colic in breastfed infants: a randomized, double-blind, placebocontrolled trial. J Pediatr 2013; 162: 257-62. http://dx.doi.org/10.1016/j.jpeds.2012.08.004

12.Sung, V., D'Amico, F., Cabana, M.D., Chau, K., Koren, G., Savino, F., Szajewska, H., Deshpande, G., Dupont, C., Indrio, F., Mentula, S., Partty, A., \& Tancredi, D. Lactobacillus reuteri to treat infant colic: a meta analysis. Pediatrics 2018; 141(1): e20171811.

13.Critical Appraisal Skills Programme. CASP Randomised Controlled Trial Standard Checklist 2020. (Accessed May 27, 2021, at https://caspuk.b-cdn. net/ wpcontent/uploads/2020/10/CASP_RCT_checklis t_PDF_Fillable_Form.pdf.

14.Mi, G.L., Zhao, L., Qiao, D.D., Kang, W.Q., Tang, M.Q., Xu, J.K. Effectiveness of Lactobacillus reuteri in infantile colic and colicky induced maternal depression: a prospective single blind randomized trial. Antonie van Leeuwenhock 2015; 107: 1547-1553. Doi: 10.1007/s10482015-0448-9. 
15.Savino, F., Cordisco, L., Tarasco, V., Palumeri, E., Calabrese, R., Oggero, R., Roos, S., \& Matteuzzi, D. Lactobacillus reuteri DSM 17938 in infantile colic: a randomized, double blind, placebo-controlled trial. Pediatrics 2010; 126: e526-e533.

16.Çelix, E., \& Turgay., ö. Encapsulation and Gastrointestinal Endurance of Lactobacillus Reuteri DSM 17938 Strain with Emulsion Polymerization. Afr. J. Food. Sci 2021; 15(9): 322-328, September. Doi: 10.5897/AJFS2021.2110.

17.Kaban, R.K., Wardana., Hegar, B., Rohsiswatmo, R., Handryastuti, S., Amelia, N., Muktiarti, D., Indrio, F., \& Vandenplas, Y. Lactobacillus Reuteri DSM 17938 Improves Feeding Intolerance in Preterm Infants. Pediatr Gastroenterol Hepatol Nutr 2019, Nov; 22(6): 545-553. https://doi.org/10.5223/pghn.2019.22.6.545.

18.Xu, M., Wang, J., Wang, N., Sun, F., Wang, L., Liu, X.H. The efficacy and safety of the probiotic bacterium Lactobacillus reuteri DSM 17938 for infantile colic: a meta-analysis of randomized controlled trials. PloS ONE 2015; 10(10): e0141445. Doi: 10.1371/journal.pone.0141445. 19.Gutiérres-Castrellón, P., Indrio, F., Bolio-Galvis, A., Jiménez- Gutiérres, C., Jimenez-Escobar, I., \& López-Velálquez, G. Efficacy of Lactobacillus reuteri DSM 17938 for infantile colic, Systematic review with network meta-analysis. Medicine 2017; 96: 51. http: / / dx.doi.org/ 10.1097/MD.000000000000 9375.

20.Szajewska, H., \& Dryl, R. Probiotic for management of infantile colic: a systematic review of randomized controlled trial. Arch Med Sci 2018; 14(5): 1137-1143. Doi: https://doi.org/10.5114/aoms.2017.66055. 